\title{
SIMEFAS: Wide Area Measurement, Protection and Control System in Mexico
}

\author{
Enrique Martínez Martínez \\ Comisión Federal de Electricidad \\ México
}

\section{Introduction}

This chapter reports on the development of a Wide-Area Measurement System in Mexico entitled SIMEFAS (Sistema de Medición Fasorial). It has been designed to increase the security and integrity of Mexico's electric power system. Current development of SIMEFAS includes five regional PDCs to which phasor data is sent by PMUs spread over the National Electrical System. Developed applications include model-validation, computation of operation and performance curves, automatic generation and load shedding, adaptive relaying, and CCVT monitoring. SIMEFAS's architecture as well as future development plans are also presented. The remainder of this chapter is organized as follows. Section 2 gives a description of SIMEFAS and the initial deployment stage of the system. Section 3 discusses the structure of the Mexican National Electrical System and of SIMEFAS. In Section 4, the main applications that have been deployed and considerations for the deployment of future applications are presented. In Section 5, the architecture and hierarchy levels of SIMEFAS is presented. Section 6 discusses the Local Control and Protection Actions Using Synchronized Phasor, and in the section 7 the Wide Area Protection Scheme using PMUs in SIMEFAS is presented.

\section{Description of SIMEFAS}

During the 1990's Mexico's Federal Electricity Commission (Comisión Federal de Electricidad, CFE) envisioned a project that consisted of the deployment of a synchronized phasor measurement system for contingency analysis, and visualization of the operational state of the National Electrical System (Sistema Eléctrico Nacional, SEN). The initial stage of this project consisted in the installation of fifteen Phasor Measurement Units (PMUs) in two of the four subsystems that comprise the National Electrical System. The installation criteria for the PMUs considered included larger generation complexes, major load points, and critical power transfer interfaces. In the initial stage post-fault analysis and model validation of power system simulator models have been of primary interest. In the second stage, a synchronized phasor measurement system for the security and integrity of Mexico's electric power system, namely SIMEFAS, has been proposed. SIMEFAS includes visualization and real-time decision applications whose main aim is to guarantee reliability and security for the National Electrical System. With the current fiber optic infrastructure installed by CFE, 
SIMEFAS acquires major importance, enabling the application of special protection schemes and discrete controls. SIMEFAS has also promoted international participation within NASPI (North American Synchropahsor Initiative), which proposes the integration of phasor measurement information between Canada, USA, and Mexico. The infrastructure developed by CFE allows the installation of a phasor data concentrator (PDC) at each transmission region giving rise to regional wide-area measurement systems at very low cost. This infrastructure also allows the integration of PMUs from different manufacturers and models and to take advantage of the PMU functions implemented in digital relays within discrete control schemes and substation control modules. SIMEFAS has provided data for fault recording analysis, database validation, contingency simulation, and prototype adaptive protection (E. Martínez 2002) and discrete control applications through the calculation of angular differences (E. Martinez 2008).

\section{Structure of the National Electric System of Mexico and SIMEMAS}

The functionality of a wide-area measurement system is based on the operational philosophy and structure of electric power systems. This is the main reason why many of the WAMS that operate successfully worldwide have been built by transmission system operators and utilities. Based upon the state of the transmission network and the requirements from economic dispatch, these entities are able to adapt phasor measurement data to the visualization and information needs of their operators and users of specific applications (S. H. Horowitz 1987 and D. Karlsson 2001).

At CFE the key to the development of SIMEFAS has been the integration of PMUs, digital relays, and disturbance recorders with PMU functionalities to regional PDCs.

As of November 2007, the National Electrical System is formed by three main electric power systems that operate independently (see Fig. 1):

- National Interconnected Power System (Sistema Interconectado Nacional)

- North Baja California Electric Power System (Sistema Eléctrico de Baja California Norte)

- South Baja California Electric Power System (Sistema Eléctrico de Baja California Sur)

Based on the topology of the National Electrical System, three phasor data concentrators were installed one for each independent power system. The number of PMUs in each concentrator will depend on the information requirements from each substation and each system, and also on the utilization of the phasor measurement data which may be used by protection specialists, analysts, system operators, etc.

For off-line analysis, the installation of GPS-synchronized PMUs represents $90 \%$ of the project. Meanwhile, for real-time visualization and real-time decisions in the power system, the communications infrastructure surpasses $95 \%$ of the project. The main reason is that to obtain reliable angle measurements in the PDC information has to be transmitted in a predefined bandwidth that allows synchronization of PMUs with minimum delay and continuous flow (V. Centeno 1993, E. Martinez 2006). 


\section{Main Applications within SIMEFAS}

CFE has established short- and mid-term goals to enable the following four applications within SIMEFAS:

1.1. SIMEFAS Off-Line, Post-fault analysis

1.2. SIMEFAS RT, Wide Area Measurement System

1.3. Wide-Area Protection and Control Schemes

\subsection{SIMEFAS Off-Line Analysis}

Phasor Measurement Units have been in use in Mexico since 1990s. Initial interest was in observing the power system through the eyes of the high precision synchronized measurement system provided by the PMUs. The data obtained from the PMUs over the years has been invaluable in observing under-damped low frequency oscillations on the network, and the performance of protection systems during power system disturbances.

On March 10, 2005 two of the four electric systems in Mexico (Northwest and the National Grid), which had operated asynchronously until that date were synchronized. See Figure 1. As soon as the tie-lines were connected and the systems synchronized, sustained inter-area oscillations were observed throughout the system which eventually led to separating the systems again. These low frequency oscillations spread throughout the whole power system of the country, especially affecting the most remote points in the network, subjecting the generators and turbines to extraordinary control actions and putting at risk the integrity of the whole Electric System.

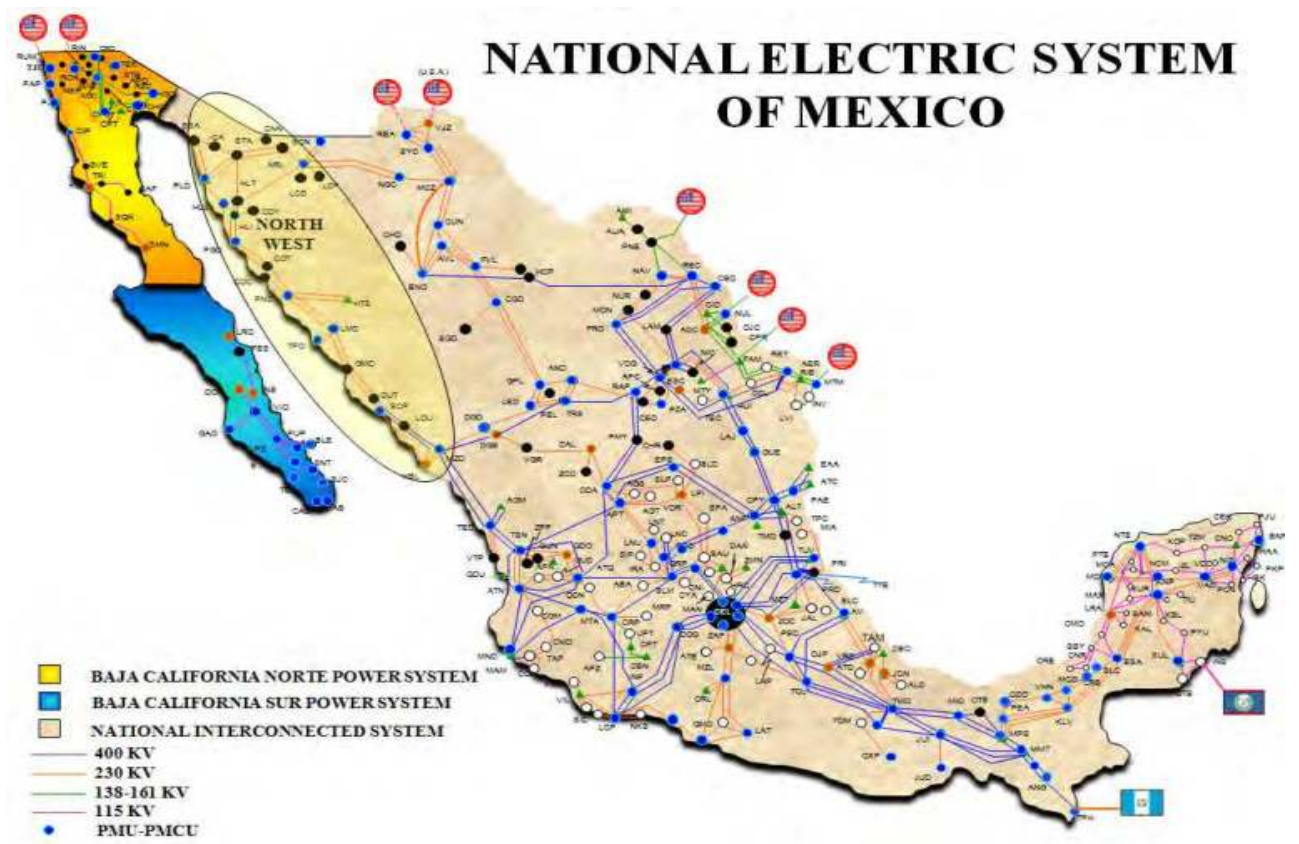

Fig. 1. Three independent systems in the National Electric Network of Mexico 2009 
The challenge for the engineers of CFE was to determine the origin of these oscillations, to determine the oscillation modes and the participation factors of main generators in the two systems. This process required many simulations for different conditions of generation, load and network configurations. The PMU recordings were the most important tool in investigation and analysis performed to determine safe procedures for the interconnection. Thanks to Wide Area Measurement System implemented in the CFE, it was possible to record and simulate the oscillations that were present during the synchronous operation. The strategic location of the PMU's was a decisive factor in the analysis and the visualization of the oscillations in real time. PMUs also make possible direct visualization of power system frequency, voltage, phase angle, active and reactive powers etc. Figures $2 \& 3$.

\section{FREQUENCY IN THE SYSTEMS DURING SYNCHRONIZATION 09-03-04}

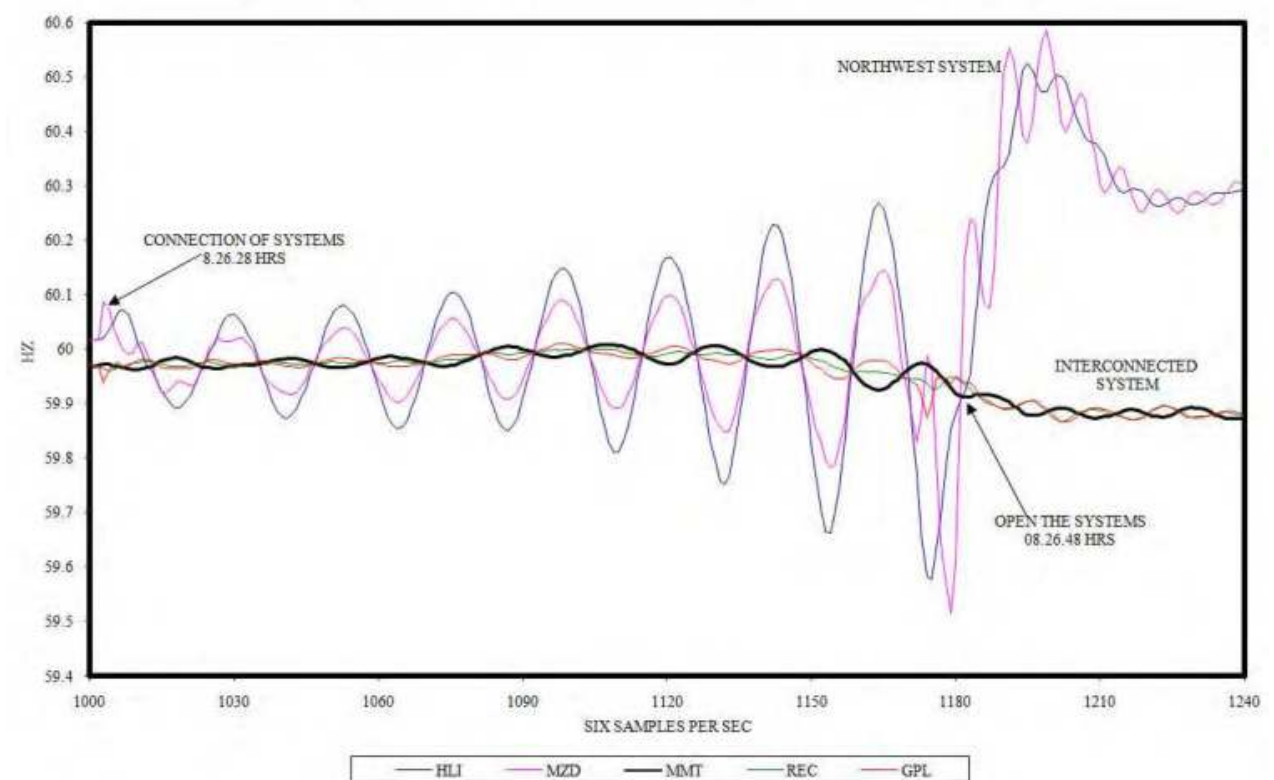

Fig. 2. Undamped inter-area frequency oscillations in both systems during synchronization in March 092004. 


\section{VOLTAGES IN THE SYSTEMS DURING THE SYNCHRONIZATION 09-03-04}

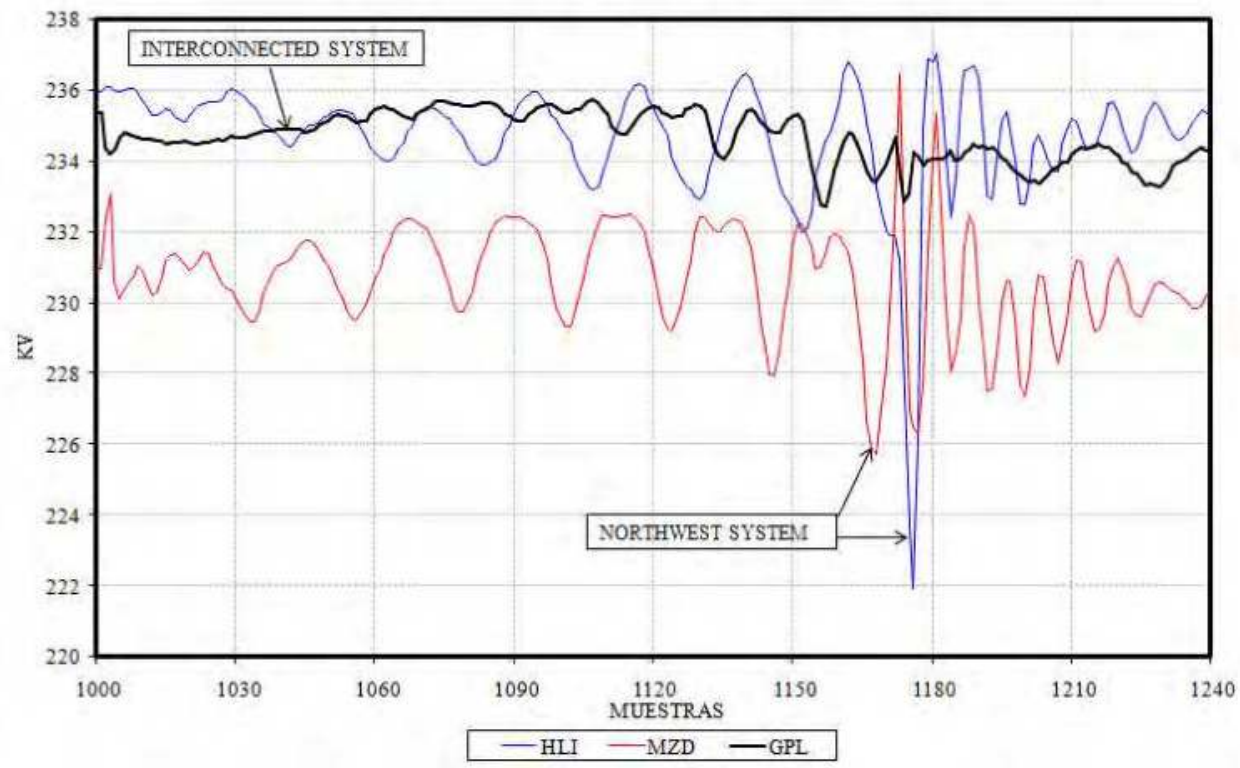

Fig. 3. Undamped inter-area voltage oscillations in both systems during synchronization in March 092004.

However, to find the origin of the oscillations and to the correct settings for excitation controls, power system stabilizers of generators it was necessary to calculate the curves of Real Power vs Frequency (P-F) and Reactive Power vs Voltage (Q-V) of machines and connection circuit among systems. Figures $4 \& 5$ show the behavior of speed and voltage regulators of generators with strong participation in an un-damped oscillations present during 20 seconds of systems interconnection.

At the moment, the systems operate interconnected through different points and voltages levels, however we continue the studies that allow us to detect power oscillations that put in risk the stability and integrity of the electric system in Mexico.

Using the records obtained with the PMUs during diverse interconnection tests, and contingencies records that have been presented in the interconnected systems, now we are studying the third dimension curves P-F and Q-V.

In this three dimensional analysis, figs. $6 \& 7$ shows the same graphs as figs. $4 \& 5$ but, in the time. Let us observe that the circuit that interconnected the systems only has frequency when it is opened (without real power in the circuit), this is due to the fact that the voltage is connected to bus PT.

In the future, the off line analysis will make it possible to implement in real time the detection of risks of instability, using Phasors Measurement Units, and establishing limits with alarms for oscillations of P-F, Q-V, P-V, etc curves, for generators, tie lines or critical points of systems during various levels of load, generation or for different system configurations.

In this process of interconnection of systems, the PMUs also has been very important in analyzing the effect of the oscillations in the transmition line protection schemes. See fig. 8 


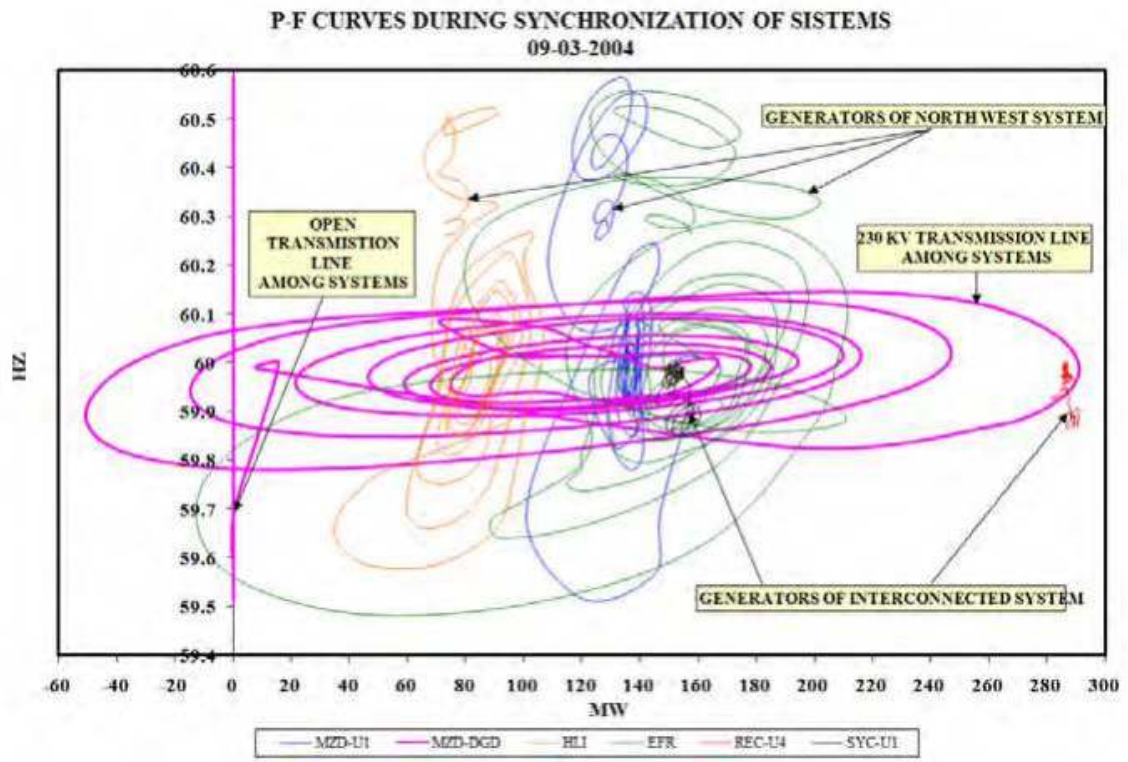

Fig. 4. P-F curves of the generators with larger participation in the oscillations during the interconnection of systems. March 092004.

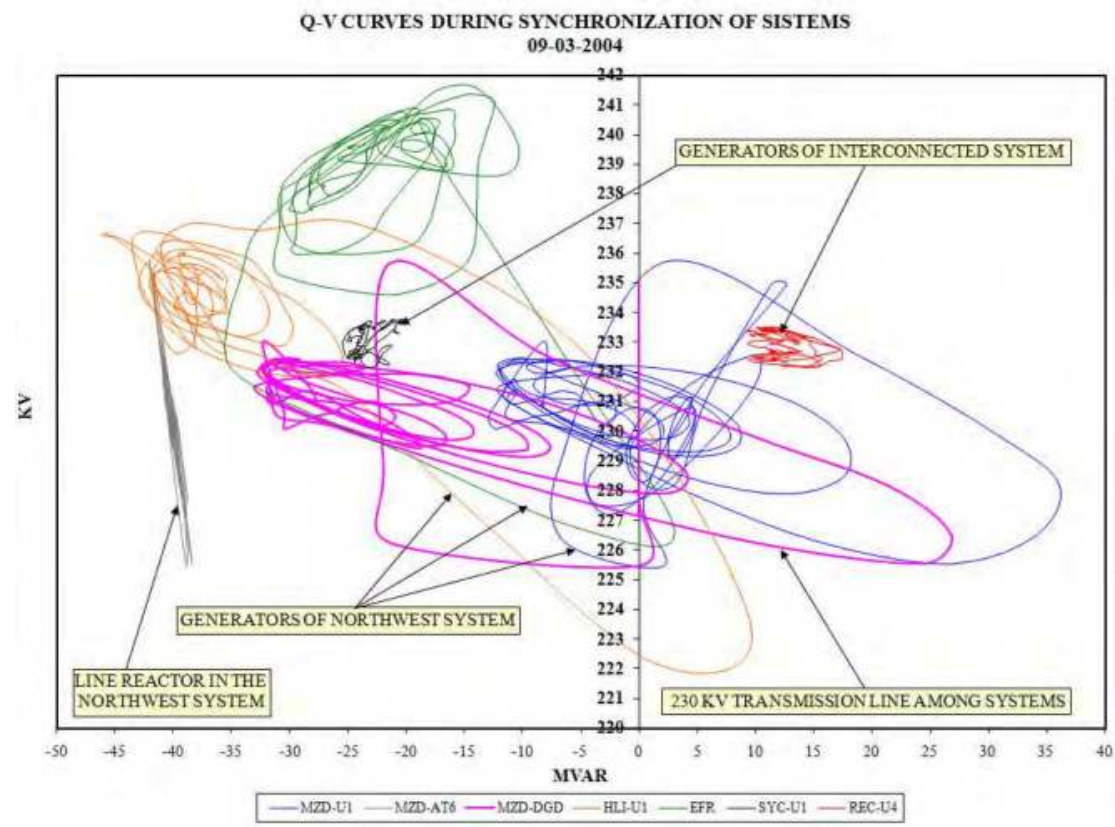

Fig. 5. Q-V curves of the generators with larger participation in the oscillations during the interconnection of systems. March 092004. 
P-F CURVES IN THE TIME

ACTIVE POWER IN THE CIRCUITS DURING THE SYNCHRONIZATION IN MARCH 092005

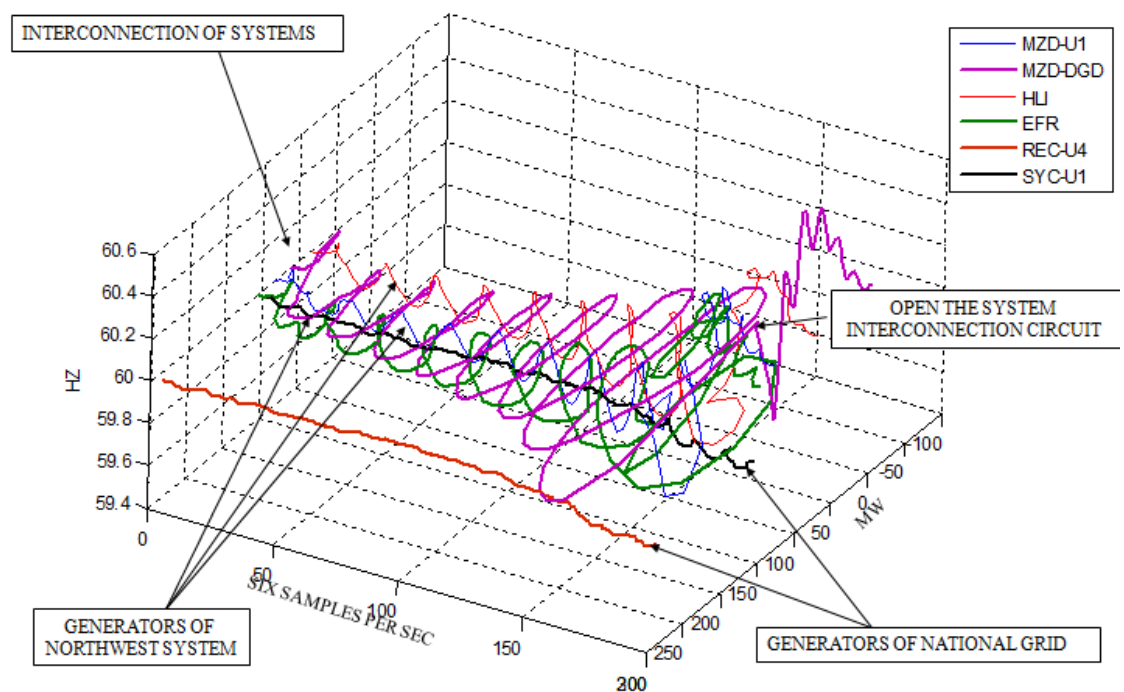

Fig. 6. P-F curves during 20 seconds of systems interconnection.

Q-V CURVES IN THE TIME

REACTIVE POWER IN THE LINES DURING THE SYNCHRONIZATION IN MARCH 092005

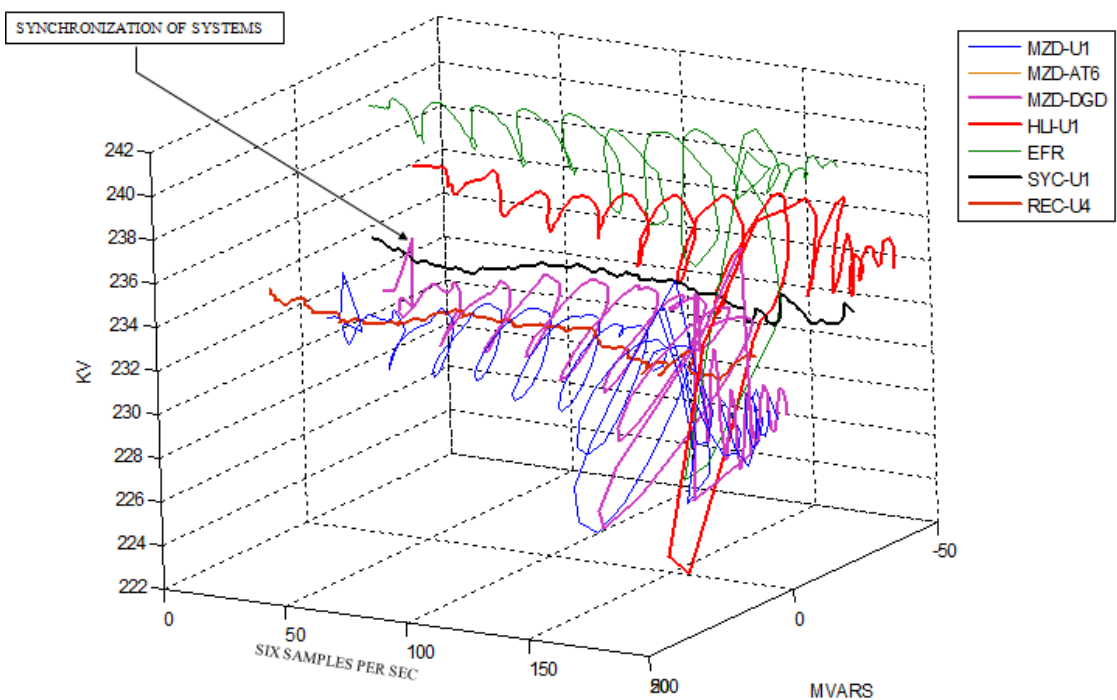

Fig. 7. Q-V curves during 20 seconds of systems interconnection. 


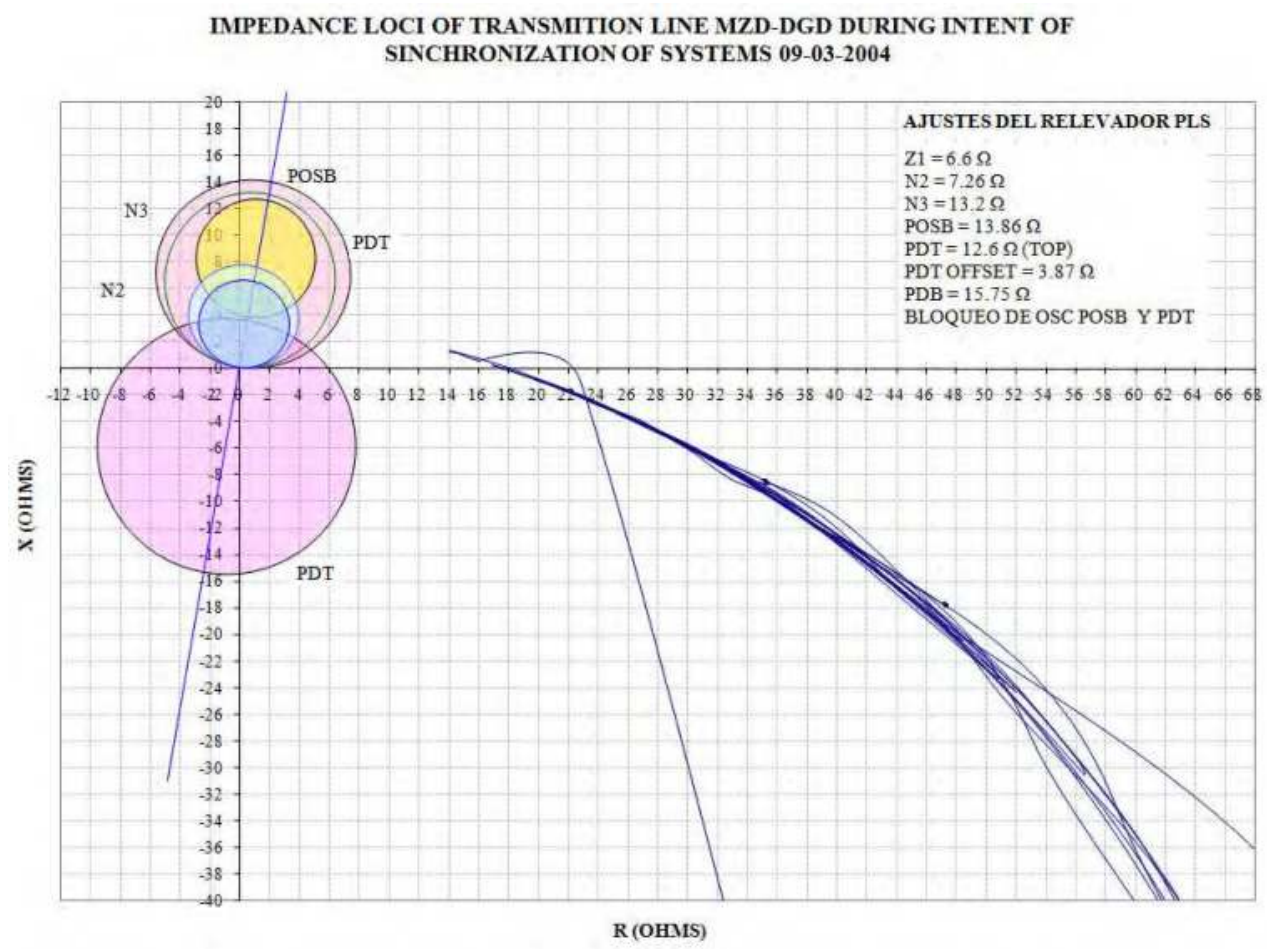

Fig. 8. R-X curves during 20 seconds of systems interconnection.

Currently data recording no longer requires triggering, and is done continuously, with all the information sent to regional PDCs. A sampling frequency of 20 samples per second for all the PMUs installed within the National Interconnected Power System, and of 30 samples per second for the PMUs at the North Baja California Electric Power System. The sampling rate at North Baja California was selected to share the same sampling rate as the one proposed by NASPI that will coordinate all the phasor measurement from NERC. The information is stored in batches of 5000 samples. However, these information packets can be made smaller if the number of installed PMUs is larger or if the archival procedure requires large amounts of memory or time.

For off-line data analysis and applications it is important to have a sufficiently high sampling frequency, reliable data capture, and precise signal processing. These requirements intrinsically depend on the technology of the PMUs. For these applications the communications infrastructure does not affect the reliability of the analyses. 


\subsection{SIMEFAS-RT Wide Area Measurement System}

For this application it is important to have high-quality PMUs and a reliable and secure communications system, preferably based on fiber optic, interfaces and routers with sufficient bandwidth.

To provide operators with adequate signals for corrective or preventive actions, state visualization requires high speed data transmission because the computation of angle differences is done in real-time as the samples of each PMU reach the PDCs. See fig. 9

Sampling frequency is determined by the requirements of each specific real-time application, dynamic or transient. In other countries there are applications that use two samples per cycle requiring high bandwidth from the communication channels and large memory capacity of PDCs for data storage.

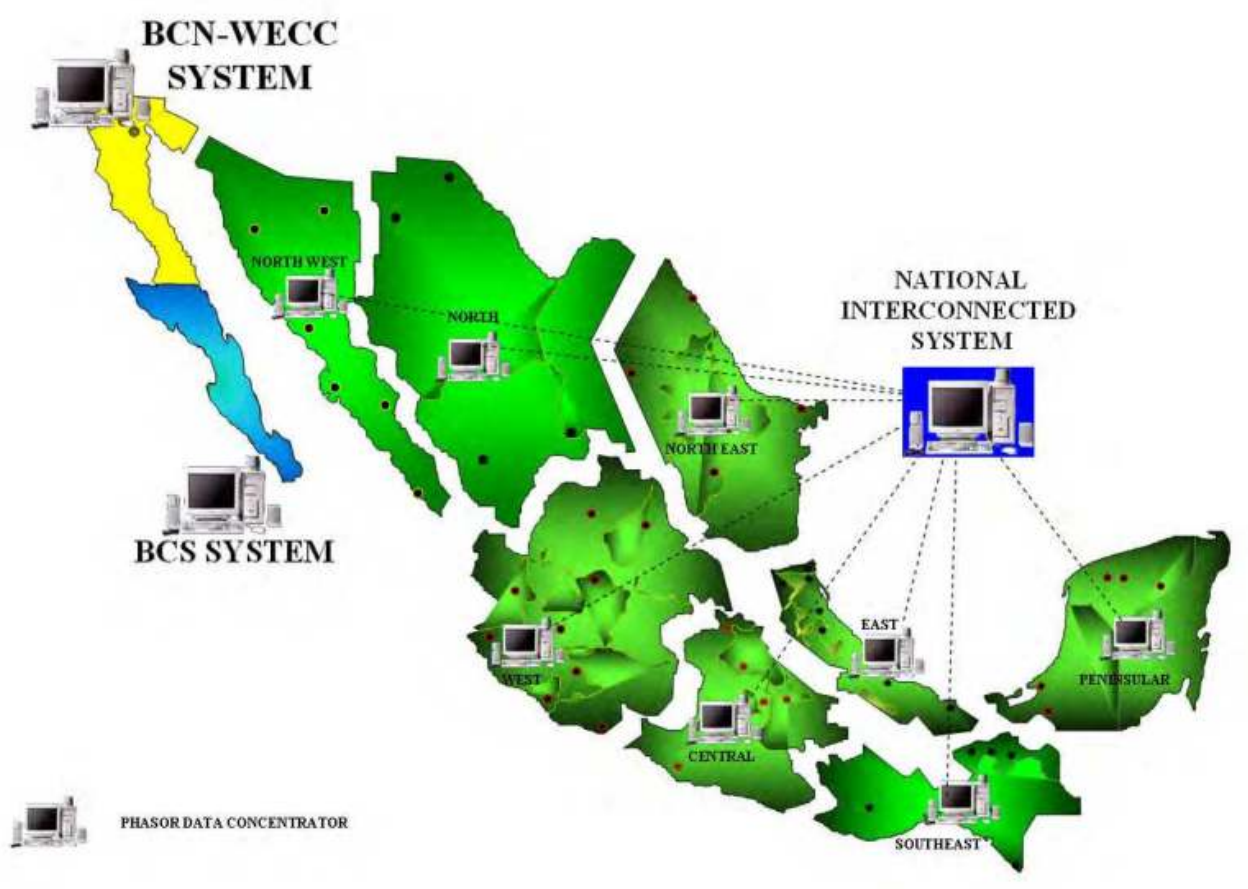

Fig. 9. Regional PDCs and integration of few strategic PMUs into the single PDC of the National Electrical System

\subsection{Wide Area Protection and Control Schemes}

Currently CFE is developing an adaptive protection scheme based on the angular difference between subsystems. CFE is also performing field test data analysis on the behavior of a prototype generation shedding scheme which assesses the transmission capability among two hydro generation stations. The scheme has a decision logic that uses signals from the active power flow, voltage, frequency, breaker state, and angular difference between the two stations. Both the adaptive protection and generation shedding schemes are fully 
independent from the WAMS with regards of decision making for maintaining stability in the system. Nevertheless, phasor information is continuously sent to the WAMS providing visibility of isolated areas in case of islanding. See section 6 .

\section{Architecture and hierarchy level of SIMEFAS}

WAMS of CFE have been designed to satisfy the requirements from each phasor measurement data user or potential client. This has been done to cater to the speed, quantity, and type of information needs of each client depending on their responsibility area and security.

Fig. 10 shows pyramidal architecture. The base is formed by the network entities that manage local data, i.e. substations and generation stations. At this level the local data transfer speed requirements to PDCs are lower than local data management requirements. At the highest level less local PMU information is required for obtaining a broader visibility of the overall system, this requires a higher information transfer speed than at the lower levels.

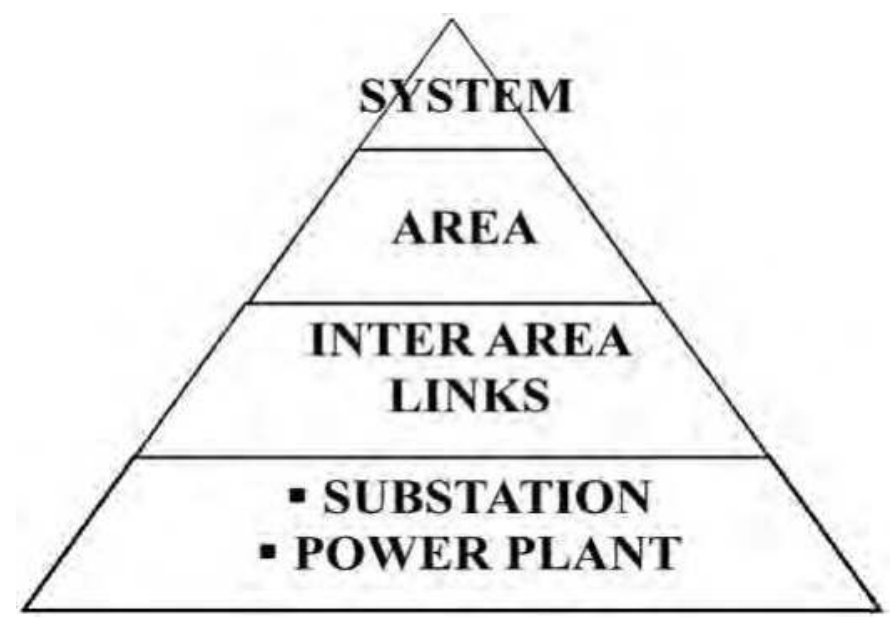

Fig. 10. Data management structure. SIN: National Interconnected Power System (Sistema Interconectado Nacional, SIN), Regional Control Task Manager (Gerencia Regional de Transmisión), Interarea Ties (Enlaces interareas), Substations (Subestaciones), Generation Stations (Centrales Eléctricas).

\subsection{First level: Substations and Generation Stations}

At this level data transfer speed is not of primary concern and applications are unlimited. Applications are local and independent; however, it is possible to send a lower amount of information with higher speed to PDCs to enable the functioning of a Real-Time WAMS. At CFE we have seen that at this level the use of PMUs or disturbance recorders with PMU functions have shown more advantages over digital relays with PMU functionalities. The main current and voltage phasors being monitored in a substation will share the same time tags, which is important when analyzing the response of machine clusters, automatic 
voltage regulators, stabilizers, and the AGC. Common monitored variables from PMUs at this level are frequency, voltage, phase angle, active and reactive power. These variables have been used to compute $R-X, P-f, Q-V$, and $P V$ curves. See fig. 11

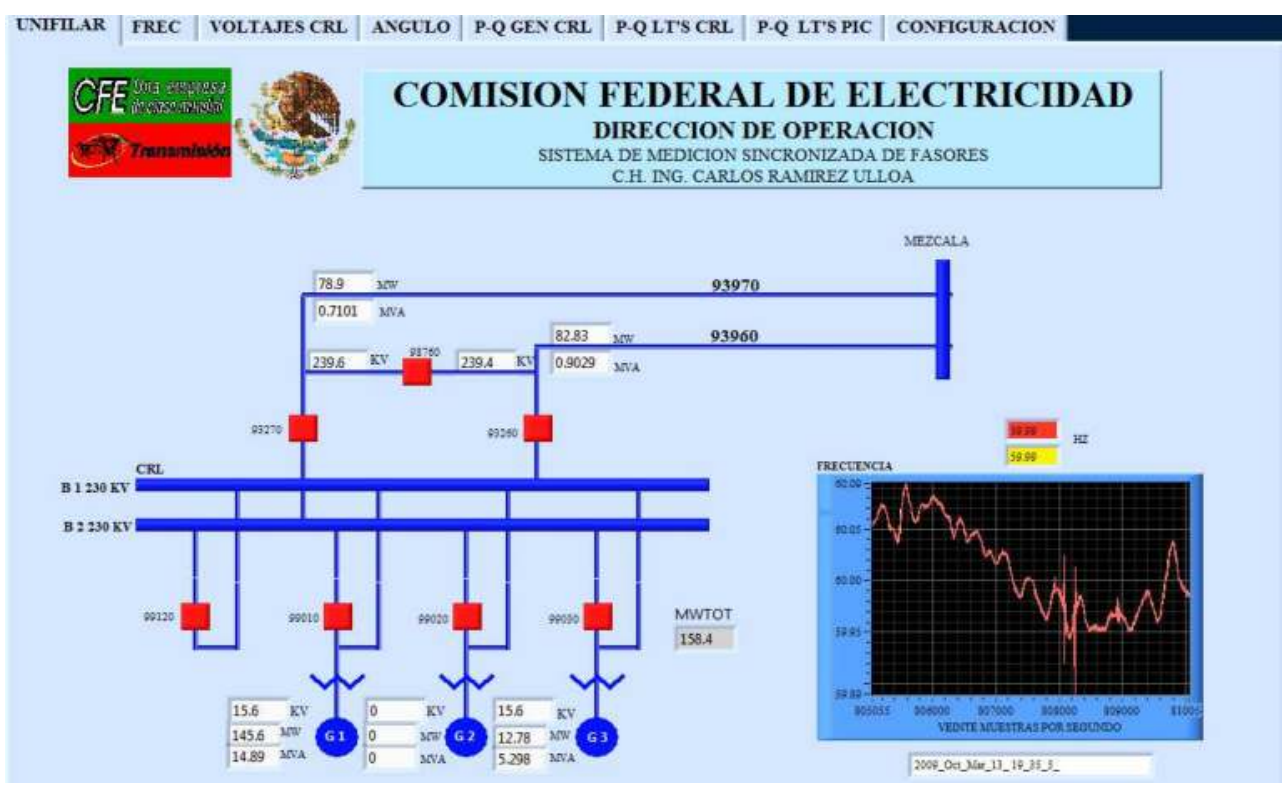

Fig. 11. Special application of PMU in a power plant for oscillation and PSS actions analysis.

\subsection{Second level: Inter Area Links}

This level is important for the analysis of the behavior of critical inter-area ties which have shown small signal oscillations or power flow inversions that have impact on transmission line protection schemes.

At CFE, one of the dilemmas that protection engineers have faced is on how protection schemes are enabled or disabled when power oscillations appear. Triggering of protection schemes requires monitoring of the magnitude, speed, and frequency of oscillation of the modes involved. This permits maintaining stability and load-generation balance when large disturbances occur in the system.

Also, CFE has developed other special applications for the monitoring of connections critics with restrictions in the power transmission or low frequency oscillations circuits by radial topology of systems, is the case of the interconnection Mexico- Central America through Guatemala in 400 kV. Fig. 12 


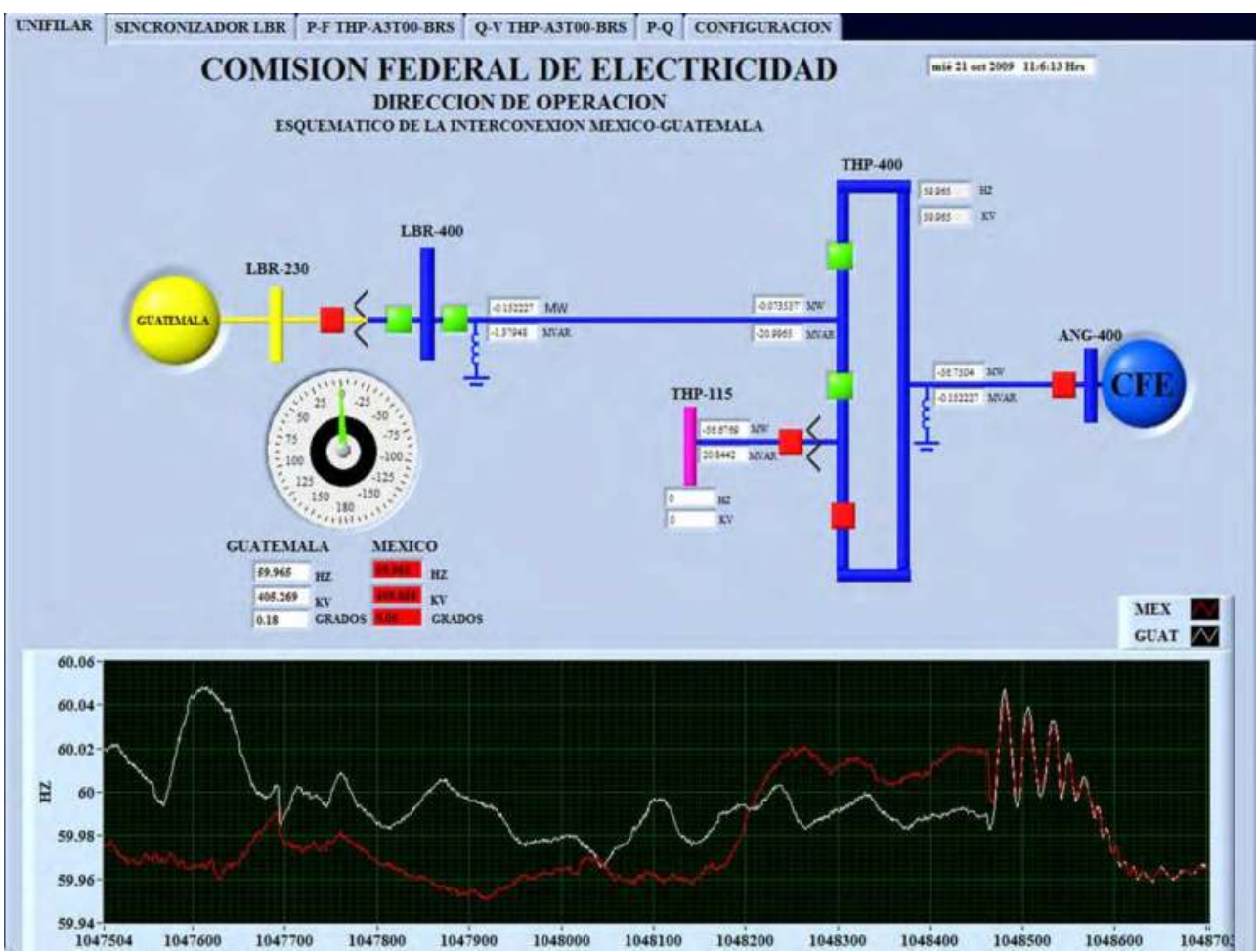

Fig. 12. Special application to study inter systems oscillations, during interconnection of Mexico-Guatemala systems.

\subsection{Third Level: Regional PDCs}

At this level the main goal is to guarantee efficient information management and to provide appropriate maintenance to the PMUs and PDCs installed by each Regional Transmission Manager (Gerencia Regional de Transmisión). These are shown in Fig. 9 Location of PDCs.

CFE has considered using the wealth of available information for real-time visualization of each regional area independently and to apply it in transformer bank and transmission line loading studies, energy interchange, power quality, and the behavior of protection and relief schemes. Fig. 13 


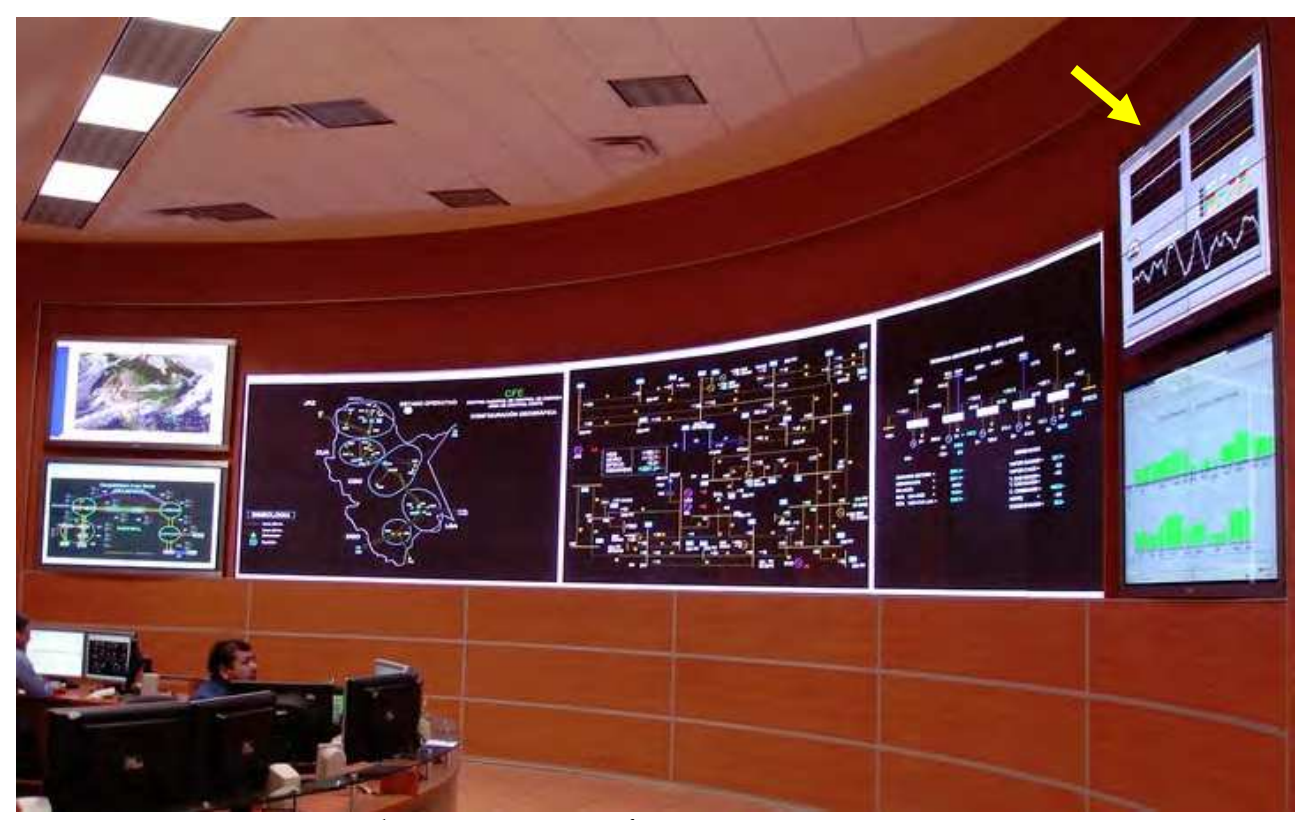

Fig. 13. Using PMUs in real time operation of power system.

\subsection{Fourth level: Central PDC SIMEFAS}

CFE has considered using the wealth of available information for real-time visualization of each regional area independently and to apply it in transformer bank and transmission line loading studies, energy interchange, power quality, and the behavior of protection and relief schemes. CFE has designed to integrate all the information from the regional PDCs and from strategically placed PMUs into a single PCD for each island system. This PDC will hold the most selective information from a large number of PMUs allowing it to synchronize frequency and voltage phasor measurements with ease and to calculate phase angles accurately, giving the operator a broader view of the system state from the measurements from each selected location. To enable a state estimator it is also necessary to have active and reactive power measurements from the networks, and PMUs can provide this information. At the moment each PMU can simultaneously send the information to four different concentrators and the applications are specific of each user. The information that Integra in the central PDC does not go through the local concentrator, since this one is sent directly from each PMU through independent channels. See Fig. 14 Architecture SIMEFASNet. 


\section{SIMEFAS SYSTEM ARCHITECTURE}

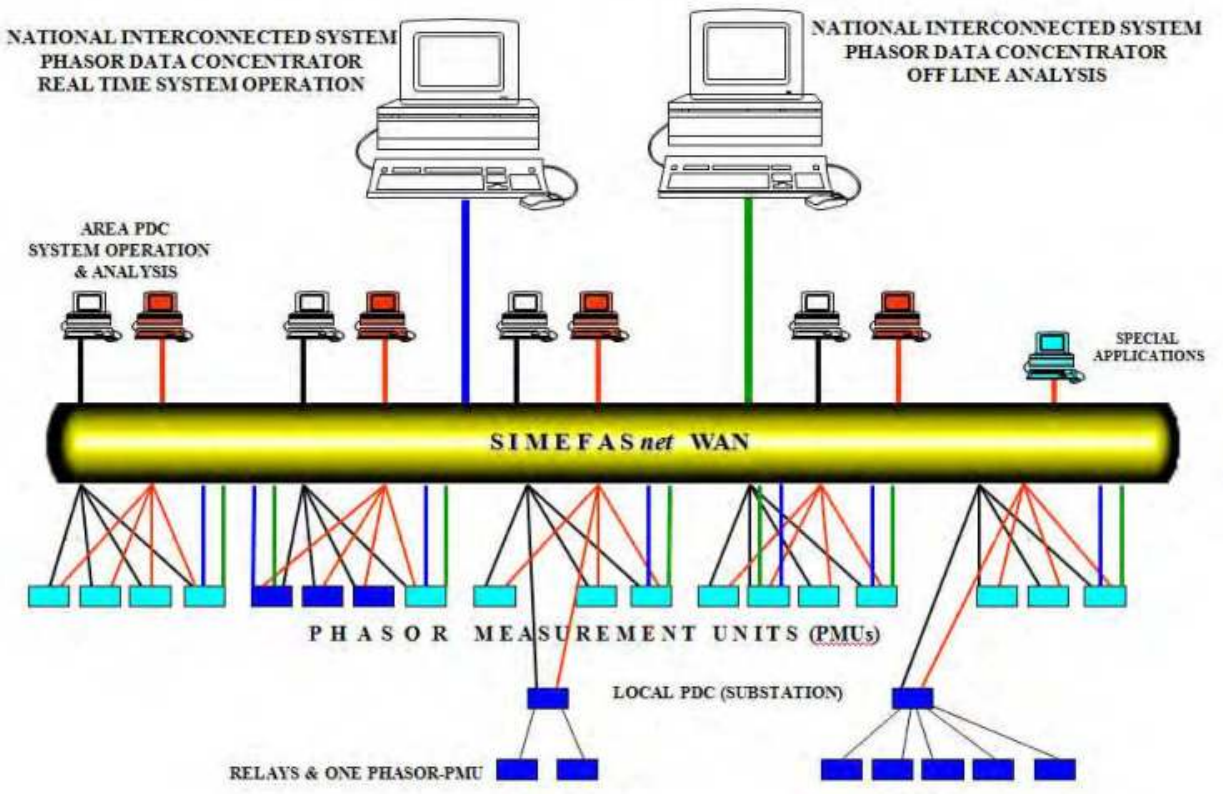

Fig. 14. Schematic of SIMEFASnet.

\section{Local Control and Protection Actions Using Synchronized Phasor}

Another application in use at CFE is the monitoring of CCVTs. Some regions in Mexico experience extreme heat and humidity conditions. CFE has observed that under these conditions CCVTs may explode. Voltage differences in the CCVT are monitored in real-time. When abnormal conditions are detected an alarm will enable and the equipment is taken out of service to protect the device, the installation, and the personnel.

Based on registers obtained by PMUs, we have identified the CCVT behavior model minutes before its explosion and we determined the alarm times or transmition lines opening for the change of the transformers that put in risk the people and adjacent equipment during an explosion, which in addition, affects the service by generation or load trip, since during this phenomenon all the substation can be lost. See fig. 15 
LINE YOLIAGE CDD-93!)70-PLA DURING CCVT IALL KE PILASE "C"' 14-03-05 23:30 $11 \mathrm{KS}$

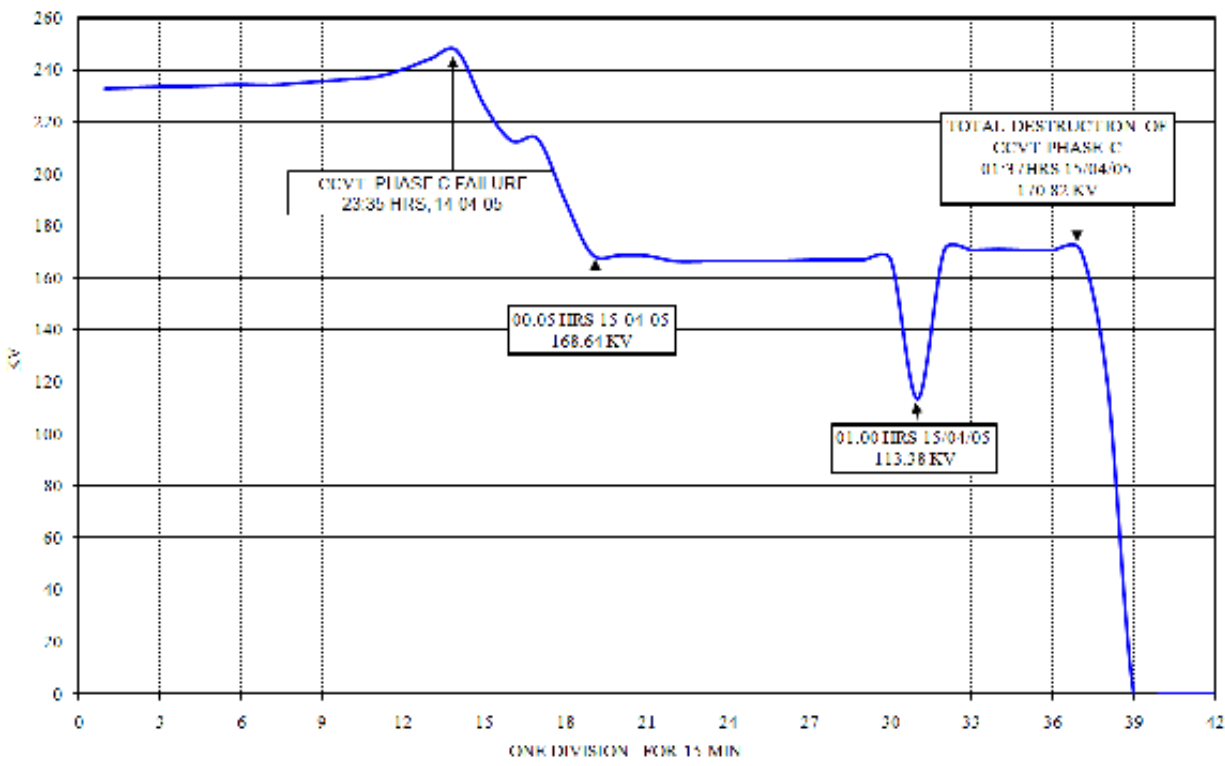

Fig. 15. Application of PMUs for substations local control actions, based on analysis of voltage behavior CCVT.

\section{Wide Area Protection \& Control Schemes}

Recently some relay manufacturers have implemented PMU functionalities in distance and overcurrent protective schemes, these prototype schemes or Phasor Measurement and Control Units (PMCUs) provide the assignment of logical variables in devices. In angular instability triggered-based automatic generation or load shedding applications the Phasor Measurement and Control Units PMCUs must take control actions independently from the GPS signal, similarly as is done in differential protection schemes. This new special protection scheme, called "Angular Difference Protection Scheme", should be able to operate as a discrete control scheme and at the same time transmit measurements at the same sampling frequency and under the standard IEEE C37.118 protocol (IEEE Sinchrophasors for Power Systems 2006). In this section, we will analyze the application of the PMCUs in a remedial action called Automatic Generation Shedding Schemes (AGSSs), however, this same application principle can be used in dynamic breaker control or a load shedding action when there is a loss of a circuit in the multiple connections among areas, systems, countries or electric companies. Currently in industry, programmable logic controllers (PLCs) are used to make control actions through dedicated communication channels that allow decision making based on the pre-programmed logic. These control actions enable automatic generation shedding, load shedding, or transmission line switching. However, with this method when the system is separated through opening of tie 
lines the system operator losses control and visibility of isolated areas making the event analysis and resynchronization process complex and slow (E. Martinez 2006).

As shown in several studies, wide area monitoring, protection, and control systems (WAMPAC) are required to measure, evaluate the measurement, and return the control action commands. This process requires high reliability and speed in the communications system to provide control actions when necessary, or to detect false triggers. Thus measurement, protection and control concepts need to be integrated within these systems. CFE's WAMS integrates different PMU brands and models. CFE is installing these relays to perform control actions based on voltage angle differences calculated at different locations in the power system. The success of these applications depends on the ability of the relays and communication networks to perform these tasks.

\subsection{Automatic Generator Shedding Using Synchronized Measurement}

The real power transfer, $\mathrm{P}$, between two network buses connected by a reactance, $\mathrm{X}_{\mathrm{L}}$, is determined by the phase angle difference $\delta$, the voltage magnitudes at the buses, $\mathrm{E}_{\mathrm{A}}$ and $\mathrm{E}_{\mathrm{B}}$, and the reactance, $X_{L}$ (see Fig. 16). Notice that the angle at Bus B (reference) is 0 . The two buses exchange real power according to Equation 1.

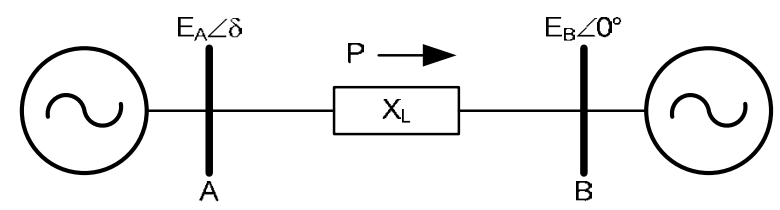

Fig. 16. $\delta, \mathrm{E}_{\mathrm{A}}, \mathrm{E}_{\mathrm{B}}$, and $\mathrm{X}_{\mathrm{L}}$ Determine the Real Power Transfer, $\mathrm{P}$, Between Bus A and Bus B

$$
\mathrm{P}=\frac{\mathrm{E}_{\mathrm{A}} \cdot \mathrm{E}_{\mathrm{B}}}{\mathrm{X}_{\mathrm{L}}} \cdot \sin \delta
$$

During steady state operating conditions, the voltage magnitudes of the network buses are close to one per unit. That is, the real power transfer capability mainly depends on the phase angle difference, $\delta$, and the transmission link reactance, $X_{L}$. $X_{L}$ depends of the number of lines and transformers in service between the two buses. When transmission lines are lost during a system disturbance, $\mathrm{X}_{\mathrm{L}}$ increases and the angle difference also increases to maintain the same amount of real power exchange between the two buses. Fig. 17 illustrates the real power transfer capability and the real power transfer operating point as a function of the angle difference during normal operating conditions and after transmission links are lost because of a system disturbance. Notice that the increase in impedance between the system buses reduces the system maximum power transfer capability (E. Martinez 2006 and J. Rasmussen 2006). 


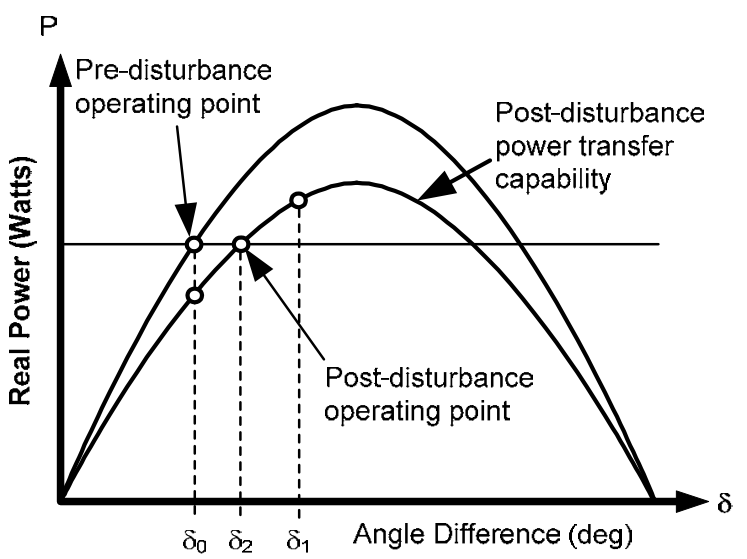

Fig. 17. Real Power Transfer Capability Mainly Depends on the Angle Difference $\delta$, or the Transmission Link Reactance $\mathrm{X}_{\mathrm{L}}$, When $\mathrm{E}_{\mathrm{A}}$ and $\mathrm{E}_{\mathrm{B}}$ Are Close to Nominal Values

For transmission links with several lines and intermediate substations, existing AGSSs monitor network topology and power transfer capability using open line detectors for arming themselves, selecting generators to trip, or activating tripping commands. Open line detectors are based on breaker auxiliary contact signals (52A or 52B,) undercurrent, and/or under-active-power elements. Usually, these AGSSs use information from both ends of each transmission line to determine if the line is open. With this angle difference information, the SPS can take action instantaneously.

The angle difference information between two buses can perform the following tasks:

- Arm an AGSS

- Trip generation

- Supervise present AGSSs to increase security

For these reasons, we propose an AGSS based on the positive-sequence voltage angle difference between two buses at different locations of the power system.

\subsection{Location AGSS in the Power System}

There are several SPSs in service in the Southeast region of Mexico because the largest load on the national system is located at the center of the country and $4820 \mathrm{MW}$ of hydroelectric generation is located at the Southeast part of the country. The distance between the heavy load region and the large generation region is $2,000 \mathrm{~km}$. The Grijalva River Hydroelectric Complex is depicted in Fig. 18. One of the SPS in service at Angostura Hydroelectric Power Plant monitors the loss of the transmission link in $400 \mathrm{kV}$ between Chicoasen and Angostura. During normal conditions, Angostura can generate up to $180 \times 5=900 \mathrm{MW}$ while the total load of Tapachula and South Chiapas region does not exceed $100 \mathrm{MW}$. The excess power in the region flows from Angostura to Chicoasen and from there to the rest of the system. If two $400 \mathrm{kV}$ parallel lines are lost between Angostura and Chicoasen, both areas remain connected through the $115 \mathrm{kV}$ network with the following consequences: 
- The transfer impedance between Angostura and Chicoasen power plants increases, causing the Angostura machines to accelerate. This machine acceleration may lead to angular instability.

- The $115 \mathrm{kV}$ network is overloaded until line or transformer overload protection operates. When this happens, Angostura and Tapachula area form a network isolated from the rest of the system.

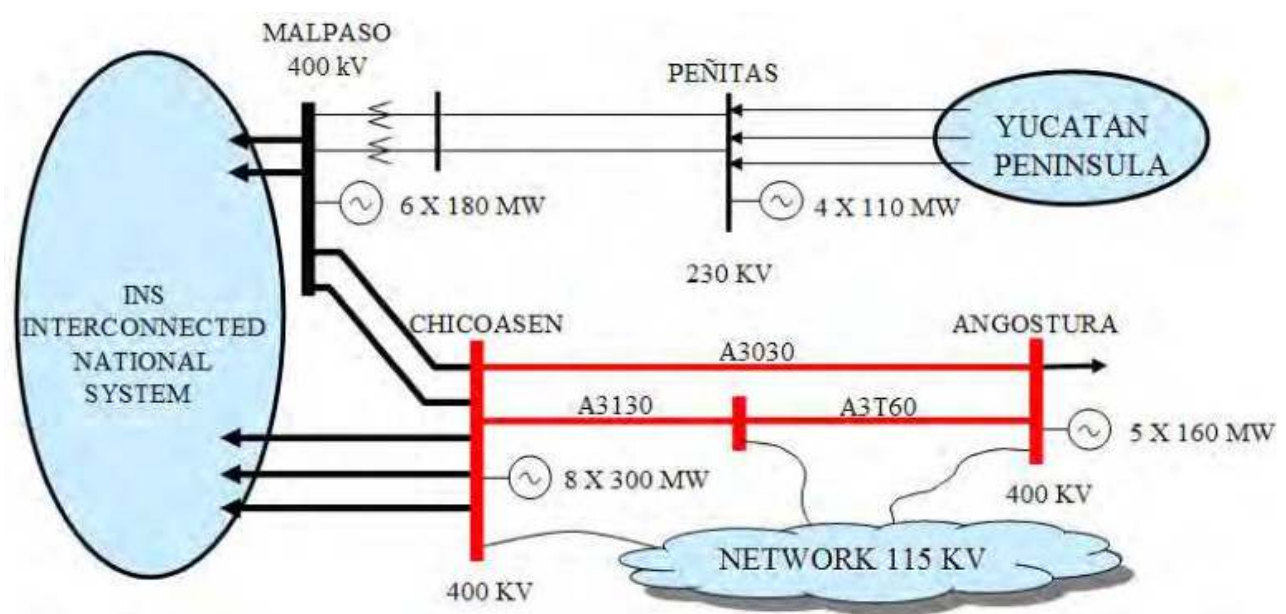

Fig. 18. Grijalva River Hidroelectric complex, Chicoasen-Angostura Transmission link with parallel $115 \mathrm{kV}$ network

For some operating and fault conditions, this double contingency could lead to a blackout at Tapachula City and south of the State of Chiapas. The following simulation results show angle differences between Angostura and Chicoasen for single (loss of one tie line) and double (loss of two tie lines) contingencies on this link with maximum generation at Angostura and Chicoasen if there are no protection or AGSS control actions taken.

Table I show PSS/ETM simulation results for steady-state and transient conditions for single and double contingencies.

Based on the following results, an angle difference threshold of 10 degrees can detect double contingencies and does not operate for single contingencies. This threshold could be used in the AGSS to trip part of the generation in Angostura. 


\begin{tabular}{|c|c|c|c|c|}
\hline Case & $\begin{array}{c}\text { Prefault } \\
\text { Angle } \\
\text { Diff. } \delta \\
\end{array}$ & Contingency & $\begin{array}{l}\delta \text { at } \\
\text { Line } \\
\text { Trip }\end{array}$ & Additional Comments \\
\hline 1 & $3.38^{\circ}$ & $\begin{array}{l}\text { Single } \\
\text { Chicoasen- } \\
\text { Angostura }\end{array}$ & $6.1^{\circ}$ & Max. $\delta$ during oscillation $8.7^{\circ}$ \\
\hline 2 & $3.38^{\circ}$ & $\begin{array}{c}\text { Single } \\
\text { Angostura-Sabino }\end{array}$ & $5.25^{\circ}$ & Max. $\delta$ during oscillation $6.56^{\circ}$ \\
\hline 3 & $3.38^{\circ}$ & $\begin{array}{c}\text { Single } \\
\text { Chicoasen-Sabino }\end{array}$ & $4.11^{\circ}$ & Max. $\delta$ during oscillation $4.56^{\circ}$ \\
\hline 4 & $3.38^{\circ}$ & $\begin{array}{l}\text { Chicoasen- } \\
\text { Angostura } \\
\text { and } \\
\text { Sabino-Angostura }\end{array}$ & $14.69^{\circ}$ & No AGSS trip, system lost stability \\
\hline 5 & $3.38^{\circ}$ & $\begin{array}{c}\text { Chicoasen- } \\
\text { Angostura } \\
\text { and } \\
\text { Sabino-Angostura } \\
\end{array}$ & $14.69^{\circ}$ & $\begin{array}{l}\text { AGSS trip generation after } 100 \mathrm{~ms}, \delta \\
\text { at AGSS trip } 27.28^{\circ}\end{array}$ \\
\hline 6 & $3.38^{\circ}$ & $\begin{array}{l}\text { Chicoasen- } \\
\text { Angostura } \\
\text { and } \\
\text { Chicoasen-Sabino }\end{array}$ & $10.72^{\circ}$ & $\begin{array}{c}\text { AGSS trip generation after } 200 \mathrm{~ms}, \delta \\
\text { at AGSS trip } 25.55^{\circ}\end{array}$ \\
\hline
\end{tabular}

Table. 1. Simulation Results for Different Steady-State, Single and Double Contingencies

From the results shown in Table 1, the loss of one $400 \mathrm{kV}$ line on this link does not cause stability problems Fig. 19a. However, if two parallel lines are lost, simultaneously or sequentially, the system stability is lost because of power transfer limitations on the $115 \mathrm{kV}$ network. Fig. 19b shows the angle difference between these buses without control actions and when the AGSS trips one or two generators $300 \mathrm{~ms}$ after the double contingency occurs. 


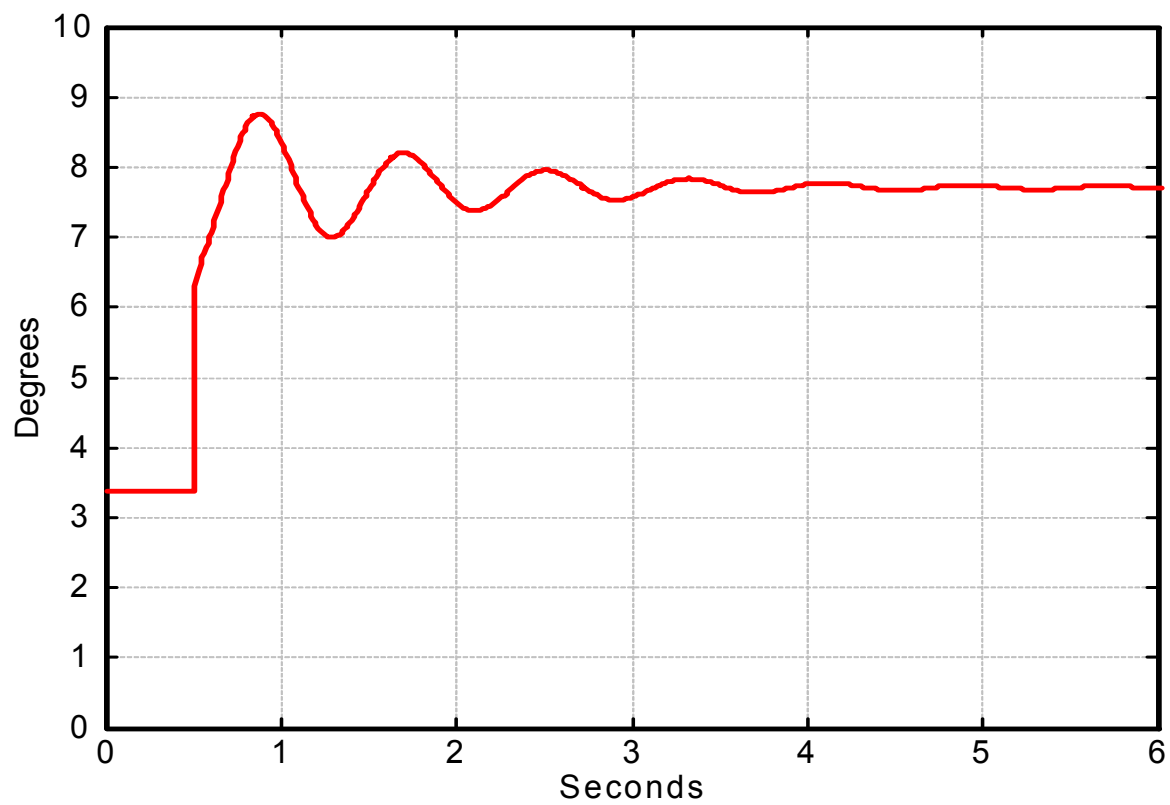

Fig. 19a Angle difference between Angostura and Chicoasen for a single contingency without AGSS Protective Action (case 1).

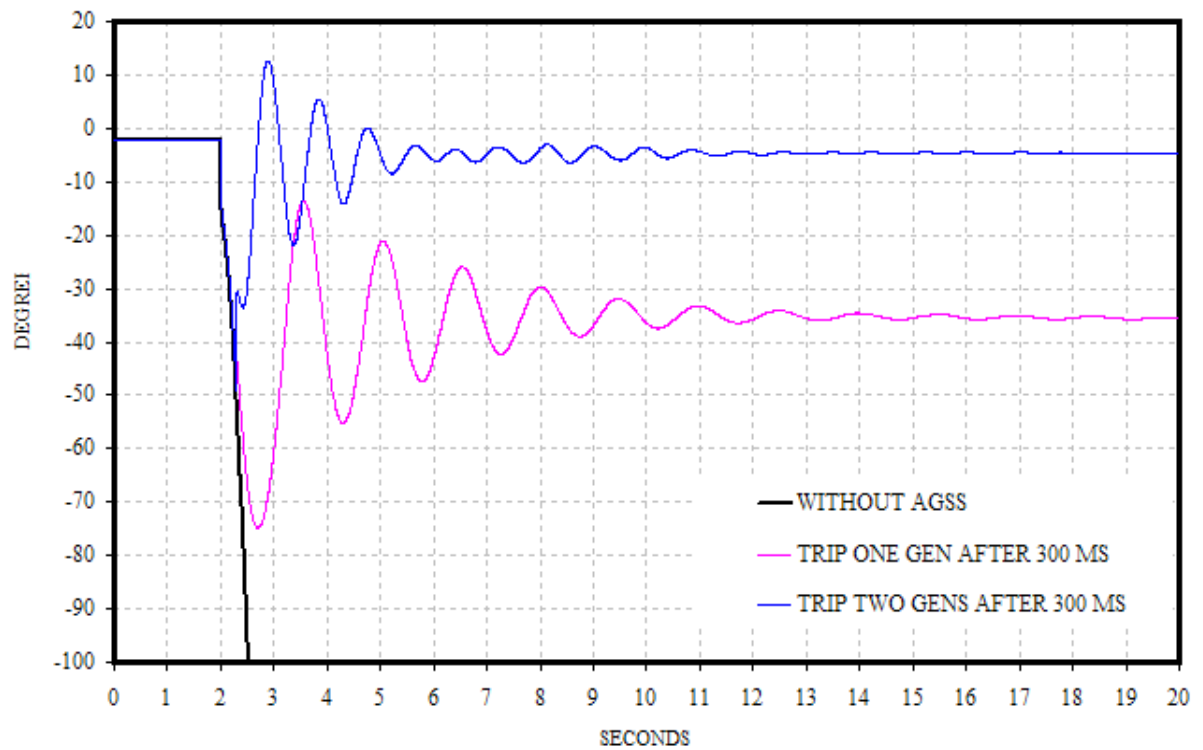

Fig. 19b Angle difference between same buses without AGSS and when the AGSS trips one and two generators $300 \mathrm{~ms}$ after the double contingency occurs. 


\subsection{Angular Differential Protection Scheme Using Synchronized Phasor}

A new proposed AGSS could use the angle difference information to make trip decisions or be used to supervise existing schemes. For this application we take into account that the Chicoasen, Sabino, and Angostura substations are directly interconnected through $400 \mathrm{kV}$ transmission lines. For this reason, the angle difference changes instantaneously at these buses when one of the $400 \mathrm{kV}$ links is lost. Fig. 20 shows the logic of the improved angledifference-based AGSS. With the added angle difference information, the logic of the scheme is simplified and depends only on one communications channel.

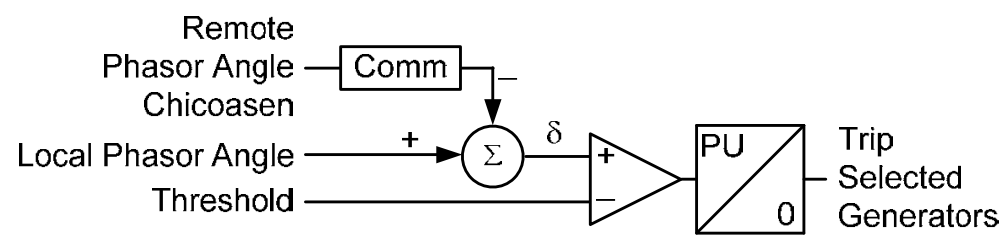

Fig. 20. Improved Angle-Based AGSS Logic

The angle difference must be compared against a threshold. If the angle difference indicates that the $400 \mathrm{kV}$ link between Chicoasen and Angostura was lost because of a double contingency condition, the scheme sheds generation. An intentional time delay may be included in some applications to avoid tripping generation or arming the AGSS during transient or fault conditions. This application does not require such delay. Appendix A has a detailed implementation description of a synchronized real-time control network.

With load flow and stability studies (Table 1), the following was determined:

- Maximum angle difference for conditions where there is no need to shed generation. Contingencies on other links, such as the $115 \mathrm{kV}$ parallel network, should also be considered to ensure that maximum power transfer is achieved between these two hydroelectric plants.

- Minimum angle difference for conditions where the system requires generation shedding. In this case, Chicoasen and Angostura are connected only through the $115 \mathrm{kV}$ network.

- Contingencies at other power system locations that affect the bus voltage angles in the region of interest need to be considered.

CFE installed the proposed scheme with continuous remote monitoring to observe the performance of the AGSS and real-time angle difference measurement during different system operating conditions and different contingencies. The measurements were validated with an accurate power system model that includes the following: generator dynamics, power system stabilizers, automatic voltage regulators, governor dynamics, and system loads.

Two PMCUs were installed, one at Chicoasen and one at Angostura. Each of the PMCUs is connected to monitor its corresponding bus voltage and currents from two lines. The PMCUs are interconnected through a fiber-optic multiplexer with EIA-232 (V.24) asynchronous interface at 38,400 bauds.

We used only serial Fast Message protocol for this test. Another serial port is connected through a serial-to-ethernet converter and sends synchronized phasor data to remote monitoring systems located at CFE regional and national offices. 
We captured synchronized phasor measurements, at a rate of 20 messages per second, during programmed line trip and close operations in the region under study with normal system loading conditions. The largest angular difference measurement between Chicoasen and Angostura, for a single contingency, occurred when Line A3030, A3130 or A3T60 tripped at Chicoasen (MMT) substation. Figs. 21a and 21b shows the network under study and the angular difference between Chicoasen and Angostura (ANG) for each condition. Fig. 21a shows the angular difference simulation results for three cases. Fig. 21b shows the same measurements angular difference. From Table 2, we can observe that these results match the measurements within a quarter of a degree. These results validate the model and the measurements.

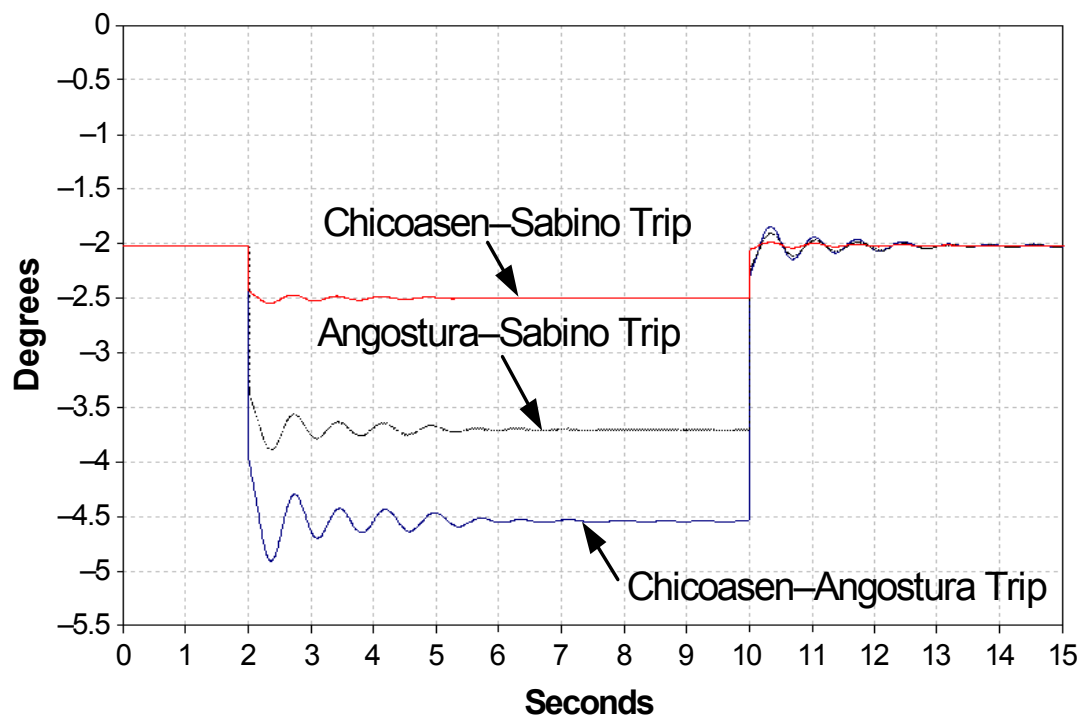

Fig. 21a Angular Difference, Between Chicoasen (MMT) and Angostura (ANG), simulation when the Line A3030 (Chicoasen-Angostura), A3031 (Angostura-Sabino) or A3T60 (Chicoasen-Sabino) Trips and Closes. Six minutes of data during the open condition are not show to shorten the graph. 


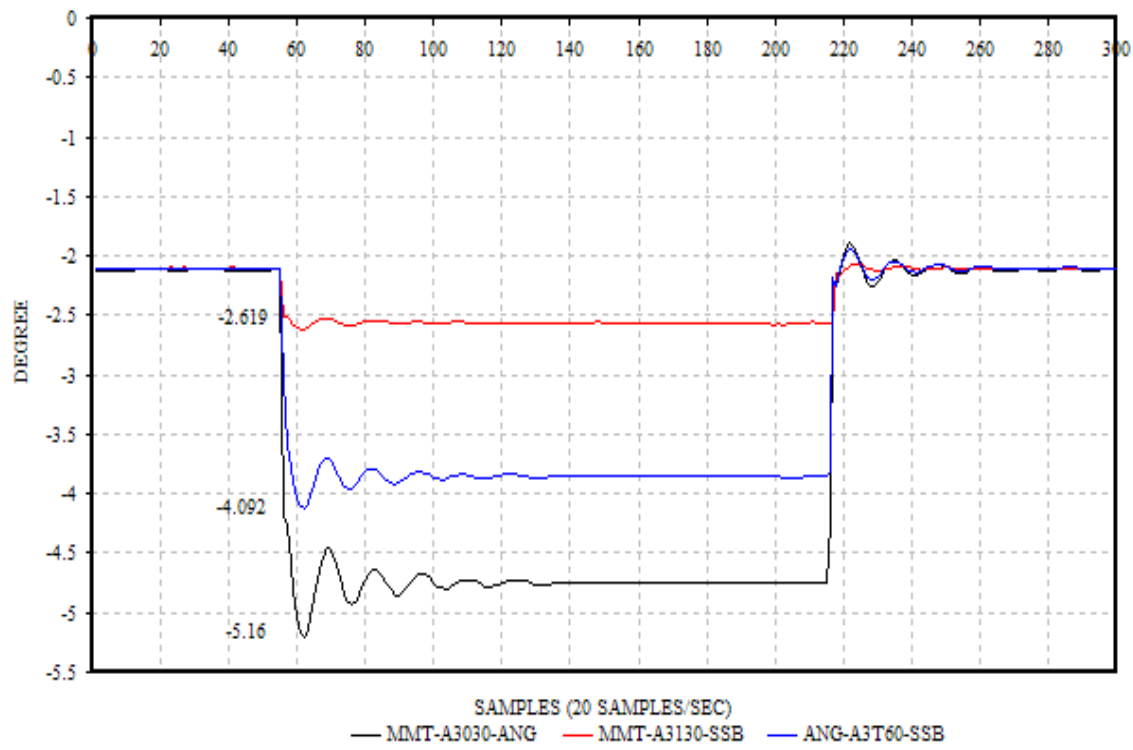

Fig. 21b Measurement values using PMUs in both substations for the same conditions.

\begin{tabular}{|c|c|c|}
\hline & $\begin{array}{c}\text { Steady-State Initial } \\
\text { Angle }\end{array}$ & $\begin{array}{c}\text { Maximum Angle During } \\
\text { Oscillation }\end{array}$ \\
\hline Simulation & $-2.01^{\circ}$ & $-4.91^{\circ}$ \\
\hline Measurement & $-2.13^{\circ}$ & $-5.20^{\circ}$ \\
\hline
\end{tabular}

Table 2. Simulation Results and Measurements. Initial Conditions and Maximum Angle Difference When Line A3030 Opens and Closes

Below are additional objectives of performing field tests:

- Test communication channel performance and communication interfaces

- Test the logic that calculates angle difference and measures scheme operating times at different angle threshold levels

We programmed four angle difference elements to test angle difference element logic and measure scheme operating time. We set the angle difference to 3, 4, 5 and 10 degrees, respectively. The oscillographic record, was taken directly from the PMCU located at Chicoasen during the MMT-A3030-ANG line trip. The oscillogram showed the current at both lines and bus voltage at Chicoasen. They operated within $92 \mathrm{~ms}$. After initial instantaneous angle change, Angostura machines accelerate, the angle difference increases, and the angle diffrence element operates after $292 \mathrm{~ms}$. 


\section{Conclusions}

- The architecture of SIMEFAS presents an alternative solution for the integration of different models of PMUs and different manufacturers under the IEEE 37.118 protocol. SIMEFAS architecture is based on PDCs that synchronizes and integrate phasor measurements through software providing a low cost alternative without limiting the integration of additional PMUs.

- $\quad$ CFE has also considered the application of SIMEFAS in monitoring of wind energy farms which are being introduced in Mexico. Continuous monitoring will improve CFE's knowledge of wind farm dynamics and will aid in the elaboration of the Network Code of the Electrical System

- $\quad$ CFE decided to evaluate the use of angle difference on this specific AGSS for three main reasons: It is one of the simplest AGSSs in the network, availability of fast communications channel and the need to accommodate future network changes in the region such as the interconnection to the Guatemala and Central America network.

- Use of PMCUs will reduce operating time and improve reliability if compared with traditional AGSSs based on traditional measurement, separate PLCs, and several remote communication channels.

- $\quad$ Fast communications channels and available PMCUs allow the angle-difference-based AGSS to operate in less than $200 \mathrm{~ms}$.

- $\quad$ Present PMCUs are able to send up to 60 voltage and current synchrophasors per second. This message rate requires a communication channel bandwidth that is not available at these substations at the moment. For this reason, CFE decided to use only voltages at 20 samples per second (one phasor every $50 \mathrm{~ms}$ ) to limit record size and bandwidth requirements. CFE would like to send voltage and currents to calculate power from synchronized phasor measurements and use it as a permissive signal, but multiplexer card bandwidths need to be changed.

- To safeguard information, CFE has developed a communications project using a Virtual Local Area Network (ViLAN) with fiber optics. It has a high bandwidth capability and TCP/IP access guaranteeing reliability, speed, and security in data transmission between PMUs.

- $\quad$ Records of angle difference measurements for single line contingencies validate measurements and simulation models. AGSS must operate only when two parallel lines are lost and studies should consider sequential or simultaneous double contingencies.

- $\quad$ CFE has not yet worked with special protection schemes that use digital relays simultaneously providing PMU functionalities and protective actions. The drawbacks are limitations on logical variable assignments in the prototype PMCUs and strong dependency of the GPS signal of each device that can affect the calculation of angular differences.

- At the moment the functions of a PMU in some relays of a fasor have been implemented, nevertheless, to implement the functions of control in a PMU, they have majors applications in schemes of protection and control of systems, since a PMU has more fasores and minor dependency of the GPS to maintain the synchronization. 


\section{References}

Daniel Karlsson and Xavier Waymel “System Protection Schemes in Power Networks” Task Force 38.02.19 CIGRE, June 2001.

E. Martínez and Juan J. Márquez "Application of Phasor Measurement Units in the Adaptive Protection of Interconnected Systems" Power Systems and Communication Systems Infrastructures for the Future. Beijing, Peoples Republic of China, September 23-27, 2002

E. Martínez, Nicolás Juárez, Armando Guzmán, Greg Zweigle, and Jean León, “Using Synchronized Phasor Angle Difference for Wide-Area Protection and Control" WPRC, Spokane, WA, USA 2006.

E. Martínez "Analysis of Contingencies with PMUs, Causes and Effects in Power Systems and Their Components" CRIS, Third International Conference on Critical Infrastructures, Alexandria, VA, September 2006.

E. Martínez "SIMEFAS: A Phasor Measurement System for the Security and Integrity of Mexico's Electric Power System" IEEE power \& Energy Society 2008 General Meeting, Pittsburgh, Pennsylvania USA 20-24 July 2008.

IEEE Synchrophasors for Power Systems, IEEE Standard C37.118-2005.

Joana Rasmussen and Preben Jorgensen "Synchronized Phasor Measurements of Power System Event in Eastern Denmark" IEEE Transactions on Power Systems, Vol. 21, No.1, February 2006

S. H. Horowitz, A. G. Phadke, and J. S. Thorp, "Adaptive Transmission System Relaying" Paper $N^{\circ} 87$ SM 625-77, in Proc. IEEE PES Summer Meeting, San Francisco, CA, July 1987.

V. Centeno, J. De La Ree, A. G. Phadke, G. Michel, R. J. Murphy, and R. Burnett, “Adaptive out-of-step relaying using phasor measurement techniques" Memoria Técnica del Segundo Simposio Iberoamericano sobre Protección de Sistemas Eléctricos de Potencia, Monterrey, N. L., México, 14 al 19 de Noviembre de 1993. 


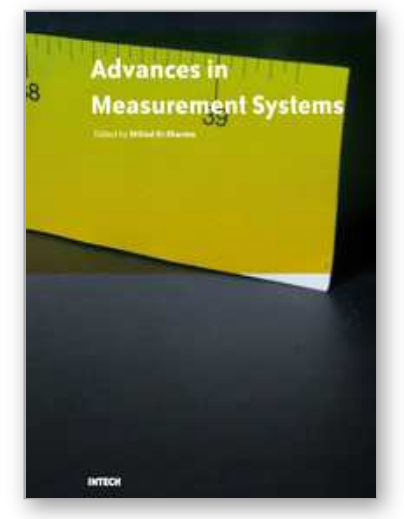

\section{Advances in Measurement Systems}

Edited by Milind Kr Sharma

ISBN 978-953-307-061-2

Hard cover, 592 pages

Publisher InTech

Published online 01, April, 2010

Published in print edition April, 2010

\section{How to reference}

In order to correctly reference this scholarly work, feel free to copy and paste the following:

Enrique Martinez Martinez (2010). SIMEFAS: Wide Area Measurement, Protection and Control System in Mexico, Advances in Measurement Systems, Milind Kr Sharma (Ed.), ISBN: 978-953-307-061-2, InTech, Available from: http://www.intechopen.com/books/advances-in-measurement-systems/simefas-wide-areameasurement-protection-and-control-system-in-mexico

\section{INTECH}

open science | open minds

\section{InTech Europe}

University Campus STeP Ri

Slavka Krautzeka 83/A

51000 Rijeka, Croatia

Phone: +385 (51) 770447

Fax: +385 (51) 686166

www.intechopen.com

\section{InTech China}

Unit 405, Office Block, Hotel Equatorial Shanghai

No.65, Yan An Road (West), Shanghai, 200040, China 中国上海市延安西路65号上海国际贵都大饭店办公楼405单元 Phone: +86-21-62489820

Fax: +86-21-62489821 
(C) 2010 The Author(s). Licensee IntechOpen. This chapter is distributed under the terms of the Creative Commons Attribution-NonCommercialShareAlike-3.0 License, which permits use, distribution and reproduction for non-commercial purposes, provided the original is properly cited and derivative works building on this content are distributed under the same license. 